\title{
Riqueza y vivienda: elementos teóricos desde la economía de las organizaciones
}

\author{
Mauricio Díaz Lozano* \\ Lina María Penagos** \\ AngÉlica MONTES*** \\ Ruth Alejandra Patiño Jacinto*****
}

\section{Introducción}

Tistóricamente, el afán por obtener riqueza ha sido natural al ser

1 humano. Todas las grandes empresas y proyectos han estado impulsados por esa motivación ${ }^{1}$, lo cual, se ha constituido en una dinámica que permea y transforma todas las dimensiones de la individualidad

* Ph. D. (c) en Estudios Políticos, magíster en Análisis de Problemas Políticos, Económicos e Internacionales Contemporáneos y economista.

* Ph. D. (c), Internacionalista y politóloga.

$\because *$ Ph. D. en Filosofía (Política y Social), Universidad de París 8. Magíster en Estudios de sociedades Latinoamericanas, Université Paris 3- Sorbonne Nouvelle, cocoordinadora del Grupo de Reflexiones y de Estudios sobre Colombia (GRECOL), en el marco del programa de las Américas de la Fondation Maison des Sciences de l'Homme (FMSH), París.

*****ánáster en Ciencias Económicas de la Universidad Santo Tomás, contadora pública de la Universidad Nacional de Colombia, coordinadora del Centro de Investigaciones de Contaduría Pública CICOP, líder del grupo de investigación - Contaduría: Información, Control e Impacto Social.

1 El haberse embarcado con tres carabelas en busca de una ruta hacia las Indias Orientales, no tuvo otra motivación en Colón y en los Reyes Católicos, más que ampliar las posibilidades de acceso a bienes que para aquella época significaban incrementar las riquezas del reino; un poco más atrás históricamente, las incursiones de los guerreros nórdicos en Europa, las guerras del Imperio romano o el Imperio persa y el afán de Alejandro Magno por conquistar Oriente, para mencionar solo algunos ejemplos, fueron al final de cuentas movidas por la motivación de obtener mayores riquezas, representadas en bienes, territorios, nuevos reinos o mano de obra esclava. 
y de lo colectivo, razones de más para que la ciencia económica haya centrado buena parte de su atención en la comprensión conceptual y formal del término.

A lo largo del tiempo, tal vez sea la riqueza el concepto que mayor preocupación haya suscitado en la ciencia económica y, por lo tanto, desde las innumerables formas de abordarlo, el que más literatura haya generado. De hecho, es el elemento alrededor del cual, escuelas económicas de importancia central como la clásica, han cimentado sus propuestas. Basta con recordar el título de la obra de Adam Smith, Una investigación sobre la naturaleza y causa de la riqueza de las naciones, de 1776, o los elementos teóricos de las propuestas mercantilistas o fisiócratas que, en el fondo de su fundamentación, lo que buscaban era brindar explicaciones sobre la naturaleza de la riqueza y las formas de obtenerla. Desde entonces, diversas escuelas de pensamiento han revisado el concepto de riqueza, lo han definido y explicado y han buscado establecer caminos para la formulación de políticas orientadas a obtenerla, mantenerla, incrementarla y distribuirla.

En este apartado se aborda el significado de riqueza desde la perspectiva teórica del institucionalismo y la economía de las organizaciones. Una primera aproximación al institucionalismo, menciona que este enfoque tiene variadas vertientes:

La clave esencial para descifrar el institucionalismo está en reconocer que no es una doctrina, sino un conjunto de doctrinas. Existe el enfoque, esencialmente de escuela histórica, de Commons y sus discípulos... Existe la economía cuantitativa de Mitchell y sus seguidores, que a menudo fue confundida con las prédicas de la escuela histórica. Finalmente, allí está el propio Veblen, básicamente complejo, desgarrado entre dos teorías que se excluyen mutuamente, atrapado en ambas durante todo el curso de su vida (Seckler, 1977, p. 37).

Bajo esta consideración, resulta relevante advertir que, además de lo expuesto por Seckler, se han configurado propuestas de importancia que conllevan nombres como Douglas North, quien se orienta más 
hacia la vertiente de un institucionalismo histórico; Oliver Williamson, quién desarrolla buena parte de sus propuestas a la luz de la teoría de los costos de transacción como institución elemental del capitalismo; autores más recientes como Daron Acemoglu y James Robinson, quiénes adoptan una postura histórica que incluye análisis de casos alrededor del mundo; Robert Boyer, Michel Aglietta, Mark Granovetter e inclusive Pierre Bordieu, quienes representan la vertiente heterodoxa del institucionalismo, que fundamenta sus explicaciones en elementos de colectividad y preponderancia en el rol del Estado como garante de las relaciones sociales y del óptimo funcionamiento de las demás instituciones, en contraposición al individualismo ortodoxo de los autores previamente mencionados; así como Ha-Joon Chang, quien plantea una interesante crítica frente a la corriente institucionalista, sobre todo frente a esa tendencia a adoptar recetas únicas ${ }^{2}$, en este caso, instituciones y ordenamientos institucionales únicos ${ }^{3}$, que buscan ser replicados alrededor del mundo: “[...] aunque pudiéramos convenir en la lista de funciones que son esenciales para el desarrollo económico, esto no significa que podamos convenir en los tipos y formas exactas de las instituciones que necesitamos para cumplir dichas funciones" (Chang, 2006, p. 127).

En la intención de abordar el concepto de riqueza y luego determinar su vínculo con la vivienda, se utilizarán elementos de las diferentes corrientes del institucionalismo, con el fin de enriquecer el andamiaje conceptual que se busca construir y, de igual manera, se acudirá bajo

2 Algo similar a lo que la heterodoxia económica critica de las propuestas neoliberales, que buscan constituirse en elementos únicos y de aplicación general (como una receta), ante cualquier problemática económica alrededor del mundo.

3 Normalmente, instituciones de origen anglosajón que han venido operando en países de esta tradición histórica, pero que, si las entendemos desde la óptica histórica del institucionalismo e inclusive desde las interpretaciones del viejo institucionalismo encabezado por Veblen (con una visión más interdisciplinar), se concluye que su implementación en tradiciones históricas tan disímiles como las latinoamericanas, las asiáticas o las africanas, es un proceso de profunda complejidad y probablemente de muy baja viabilidad. 
la metodología comparada, a la crítica o validación con otros enfoques de doctrina económica.

\section{Una aproximación al concepto de riqueza desde la teoría institucional}

El término riqueza es, sin lugar a dudas, uno de los más antiguos en el estudio de la economía política. En las ciencias económicas, los referentes más citados se encuentran en Adam Smith y David Ricardo; pero el término riqueza se remonta varios siglos atrás en el marco de la filosofía y las organizaciones políticas.

Existen diversas definiciones de riqueza; el término no apela simplemente al "estado" de un individuo o de una nación, sino al "flujo" de actividades que dan pie a su creación, ya sea para mejorar la posición social del individuo o para contribuir con el crecimiento económico mediante el desarrollo de sectores específicos que aumenten la producción. Sin embargo, se debe ampliar la definición más allá de un mero "flujo" que conlleva a incrementos en la producción: la riqueza contempla una construcción histórica, una condición y también una percepción, dependiendo del individuo y de su entorno.

El origen de la riqueza ha evolucionado a lo largo de la historia económica y, al unísono el pensamiento económico. Escuelas económicas de diversa índole han abordado su definición y los caminos para obtenerla. Entre otras: i) acumulación de metales preciosos para los mercantilistas, ii) la tierra como generadora de valor para los fisiócratas y, iii) el trabajo y su productividad para los clásicos.

El inicio de la revolución industrial marca toda una transformación en la forma en que la riqueza se concibe, se obtiene y se distribuye, ya que imprime un ritmo sin precedentes en todos los aspectos de la interacción humana y amplía las posibilidades de acceso en función del trabajo de cada agente, estableciendo nuevas relaciones sociales, económicas y políticas, producto de las transformaciones del sistema productivo.

En la obra Una investigación sobre la naturaleza y causa de la riqueza de las naciones (1776), Smith efectúa un novedoso planteamiento 
en relación con la definición de riqueza, ya que define el origen de esta en un elemento intangible al concluir que la productividad del trabajo es el elemento generador de riqueza ${ }^{4}$.

Plantea Smith que la producción con valor agregado debía traducirse en riqueza, siendo el trabajo uno de los mecanismos centrales de su creación. Esta orientación suponía la creación de riquezas a nivel variable entre los agentes económicos: trabajadores, productores y Estado. La propuesta de Smith, tiene elementos relacionados con dos principios previamente expuestos por John Locke (1689): la producción y el trabajo individual como condición para la acumulación de la riqueza.

Se encumbran realidades individuales y criterios comerciales, fundamentados en la reivindicación del individuo en toda la extensión de sus derechos y deberes, con el ánimo de consolidar mercados eficientes en donde la riqueza fuese el resultado del trabajo en condiciones naturales de un mercado competitivo, esto es, un mercado regido por sus propias normas y no por las que imponía el Estado, es decir, un mercado autorregulador.

El aporte de Smith se consolida como el primer tratado de economía política que presenta y explica de manera diferencial la obtención, consolidación y expansión de la riqueza, mediante una actividad comercial dinámica en la que el Estado reduce sus funciones a la generación de las condiciones necesarias para la libre acción de la mano invisible del mercado y el esfuerzo de cada agente determina el nivel de riqueza que podía adquirir.

Esto no es otra cosa que un nuevo orden de carácter institucional, el cual no es propiamente creado por Smith con la publicación de la obra, sino que es ya la forma en que operan los individuos bajo un

4 Smith desarrolla toda una propuesta práctica de cómo lograr incrementos en productividad para este factor productivo, partiendo de la construcción teórica que desarrolla en el concepto de "valor de cambio", uno de los elementos centrales de la teoría propuesta por la economía clásica, que posteriormente Ricardo refina para plantear, entre otras, la explicación de las "ventajas comparativas" y su incidencia en el libre comercio a nivel internacional. Finalmente, la riqueza de una nación va a depender de su capacidad para lograr constantes incrementos en la productividad del factor trabajo. 
nuevo esquema social y económico. Lo que hace Smith es explicar sistemáticamente dicho funcionamiento y plantear alternativas de optimización para el mismo.

El resultado natural de la acumulación se debería traducir en el mayor crecimiento económico de las naciones y por ende en un mayor bienestar social. Según Smith, las inequidades son resultado de un sistema con imperfecciones ante las cuales el Estado juega un rol de conciliación, más no de intervención.

Naturaleza y causas de la riqueza de las naciones, representa un legado interdisciplinar de gran envergadura por cuanto especifica la diferencia entre economía política, ciencia política, filosofía, jurisprudencia y ética para abordar de manera puntual los aspectos relativos a la acumulación y transferencia de la riqueza. Ciertamente, los ensayos de Locke permitieron un abordaje del concepto en un marco diferente en el que Smith presentó su obra: la revolución industrial y con ella, la producción en serie, el aumento de los capitales y los fenómenos de consolidación y desplazamientos colectivos hacia las grandes urbes, todos los cuales configuraron un contexto excepcional de generación de riqueza.

Ese contexto de generación primaria de capitales, transformación social y consolidación del sistema económico capitalista tiene como espacio geográfico inicialmente a Inglaterra y, posteriormente a Estados Unidos y buena parte de la Europa Central.

Ya para finales del siglo XIX el capitalismo es una realidad consolidada. En esa época surgen nuevas corrientes de pensamiento que buscan explicar científicamente todas sus implicaciones; entre ellas, se encuentra el institucionalismo, que asoma con los escritos de grandes intelectuales como Thorstein Veblen. El institucionalismo propiamente dicho comenzó en 1898 con la publicación del artículo de Veblen intitulado: ¿Por qué no es la economía una ciencia evolutiva? (Seckler, 1977, p. 39).

Esta corriente aborda el concepto de riqueza desde múltiples orillas e incluyendo elementos de todo tipo, es así, como la riqueza se interpreta desde lo más básico hasta lo más "superficial": 
Ha sido costumbre en la teoría económica -y especialmente en aquellos economistas que se adhieren con menos titubeos al conjunto de teorías clásicas modernizadas-, interpretar en lo sustancial esta lucha por la riqueza como una lucha por la existencia (Veblen, 1899, p. 27).

El consumo ostensible de bienes valiosos es un medio de aumentar la reputación del caballero ocioso. Al acumularse en sus manos la riqueza, su propio esfuerzo no bastaría para poner de relieve por este método su opulencia. Recurre, por tanto, a la ayuda de amigos y competidores ofreciéndoles regalos valiosos, fiestas y diversiones caras (Veblen, 1899, p. 80).

Sin embargo, sin mencionarlo de manera explícita, Veblen utiliza el concepto teórico neoclásico de valor de uso como base conceptual de su definición de consumo ostensible y de allí se puede afirmar que se identifican indicios de que la riqueza es también una percepción.

También se vincula la riqueza con la propiedad privada (siendo la primera la condición y la segunda la materialización) y en este sentido, algunos ven en la riqueza el conflicto que surge en la intención individual de obtenerla, lo que en términos marxistas se plantea como una lucha colectiva entre clases y que Veblen observa de la siguiente manera: "Dondequiera que existe la institución de la propiedad privada, aunque sea en forma poco desarrollada, el proceso económico presenta como característica una lucha entre los hombres por la posesión de bienes" (Veblen, 1899, p. 28).

Estas referencias sugieren al menos dos aspectos fundamentales que se relacionan íntimamente con la naturaleza de la riqueza: i) la producción como medio de obtención y, ii) la creación de valor como incentivo individual, quizá con fines colectivos. Lo relevante, es que en este último elemento de colectividad se identifica lo sustancial del enfoque institucionalista, en un marco de amplio contenido y diversidad disciplinar, el cual, desde sus diferentes aristas, aborda lo colectivo de las relaciones (reglas de juego) que se construyen mediante diversas formas, pero bajo un esquema de articulación que parte del 
individualismo: "Las instituciones son una creación humana. Evolucionan y son alteradas por humanos; por consiguiente, nuestra teoría debe empezar con el individuo. Al mismo tiempo, las limitaciones que esas instituciones imponen a las elecciones individuales son generalizadoras" (North, 1993, p. 16).

No todos los lugares del mundo desarrollaron la misma trayectoria histórica del capitalismo: mientras los contextos descritos por Veblen y North tenían lugar en aquellos países que consolidaron el sistema económico capitalista, en regiones como América Latina se generaban otro tipo de tensiones en relación con la riqueza, pero con preocupaciones aún muy rezagadas en comparación con la evolución de capitalismo:

Las implicaciones de un sistema que restringía el acceso a la propiedad fueron muy graves en el tiempo. Se daría una economía donde sobraba la tierra y aun cuando era limitada la mano de obra, las condiciones institucionales impedían que esta pudiera liberarse y obtener derechos efectivos de propiedad sobre la tierra (Kalmanovitz, 2011, p. 60).

Se deduce de lo que plantea Kalmanovitz, que, mientras en otros lugares se discutían derechos de propiedad y su entorno institucional, en esta región apenas se vislumbraba la posibilidad de acceder a los mismos. Gana entonces relevancia la crítica de Chang a ese institucionalismo, que simplemente busca implementar el modelo único que opera en determinado país o región. Se sugiere entonces, que, en definitiva, la construcción institucional se encuentra íntimamente relacionada con la trayectoria histórica, social, política, cultural y económica de cada país.

El mercado es, para la economía capitalista, una de las instituciones preponderantes y habría que preguntarse si su complejidad es el resultado de lo colectivo o de lo individual, incluso, si consideramos que esta institución es relativamente nueva en la historia de la humanidad y que su ascenso tienen que ver definitivamente con el ascenso del orden capitalista: “[...] la economía de mercado, lo olvidamos con demasiada facilidad, es una estructura institucional que no ha existido 
en otras épocas sino únicamente en la nuestra, e incluso en este último caso no es generalizable a todo el planeta" (Polanyi, 1944, p. 76).

Una de las principales funciones del mercado, tiene que ver con una adecuada y eficiente asignación de recursos, sin embargo, se ha demostrado a lo largo de la historia, que tal asignación muchas veces resulta ineficiente y las propuestas ante tal ineficiencia, se centran en una mayor intervención del Estado ${ }^{5}$ por parte de la heterodoxia o una profundización de la autonomía del mercado por parte de la ortodoxia.

En una u otra recomendación, lo que se evidencia es una construcción institucional que obedece a la idea de obtener progreso ( ¿ riqueza?), por parte de una sociedad. Tal construcción, sin embargo, en ocasiones no es tan fácil de observar, dada su complejidad y tal vez también su ambigüedad:

... aunque la infinita complejidad de una estructura institucional, desafía un entendimiento total y aunque los individuos dentro de tan respetable estructura tengan, en realidad, poco poder para emprender cambios radicales y una aversión bien condicionada al cambio drástico, no hay razón para suponer que tal estructura no sea resultado de actos adicionales de elección por parte de individuos esencialmente libres y racionales (Seckler, 1977, p. 177).

La complejidad de esa notable institución capitalista (el mercado), ha sido eje central en el análisis económico, desde Smith, quien plantea la comprensión de la formación de la riqueza como un proceso característico de la economía liberal del siglo xviı y, más allá de la relación de precios en el mercado, de la oferta, de la demanda, del utilitarismo humano y sus sentimientos egoístas en busca de la satisfacción de sus

5 El Estado es una de las más importantes instituciones de la sociedad moderna y su complejidad es de tal magnitud que ha inspirado una gran cantidad de literatura desde las múltiples ciencias sociales. Incluso desde la ciencia política ha dado para construir una teoría del Estado y desde la economía, ha sido, por supuesto, eje central de uno de los debates más profundos y antiguos, así como de actualidad, en confrontación con el mercado, institución básica del sistema económico capitalista. 
necesidades, de la construcción colectiva institucional o de las tensiones marxistas, lo que se observa es que el mercado cuenta con su propia dinámica de relaciones, que al final de cuentas se constituyen en una institucionalidad inherente al mismo y bajo la cual operan todos sus participantes, en el marco de estructuras capitalistas de gran envergadura.

La industria, el capital, la mano de obra y la producción en serie son todos elementos necesarios para la formación de la riqueza, para lo cual, la garantía de la salvaguarda del derecho a la propiedad privada es fundamental. Visto desde esta perspectiva, el rol del Estado en términos económicos es mínimo, pero no lo es así en términos jurídicos.

Esa concepción jurídica del Estado como garante legal, se relaciona de manera muy cercana a lo que plantean las corrientes institucionalistas que centran su atención en los derechos, principalmente los de propiedad, que regulan y se configuran como elementos de las reglas de juego en la sociedad: "Cada comerciante e inversionista trata con derechos de propiedad que le confieren el valor del flujo futuro de ingresos de la propiedad" (Kitch, 1983, p. 62). Frente a lo cual, existen también visiones absolutamente individualistas, que parten de la concepción clásica de que el efecto agregado es la suma de las decisiones que toma cada individuo.

Sin embargo, se deben tener en cuenta otros aspectos que influyen profundamente en tal sumatoria agregada de decisiones:

Muchos participantes en el mercado entran voluntariamente en relaciones institucionales de largo plazo, ya sea mediante contratos o por la creación de empresas que ponen a los individuos en la posición de tomar decisiones, cuyas consecuencias serán sufridas por otros (Kitch, 1983, p. 62).

La riqueza entonces, aceptando que esta se encuentra definida por las posibilidades de progreso que brindan los mercados, no depende exclusivamente del individuo, sino que también lo hace de la constante interacción de decisiones que al final de cuentas, emergen como construcciones institucionales de gran complejidad. 
Estas construcciones institucionales son también elementos de análisis, en razón de su origen y evolución. Como resultado de la interacción humana, la institucionalidad, sea cual sea, es el resultado de unas decisiones que han tomado los individuos (aquí vale la pena preguntarse, ¿todos los individuos?), y su fin esencial es brindar un espacio de confianza y certeza: "La función principal de las instituciones en la sociedad es reducir la incertidumbre estableciendo una estructura estable (pero no necesariamente eficiente) de la interacción humana" (North, 1993, p. 16).

Sin embargo, de la advertencia que hace North, en cuanto a la eficiencia institucional, es válido revisar, cuál sería entonces el aporte en términos de riqueza para una sociedad, el establecer o adoptar determinado orden institucional, si además este es el resultado de las decisiones individuales, pero no de todos los individuos, “[...] estas instituciones, o cuando menos las reglas formales, son hechas para servir los intereses de quienes tienen el poder de negociación para idear nuevas normas" (North, 1993, p. 29).

Adicionando a estas circunstancias el hecho de que las instituciones y el orden institucional (construido, adoptado o impuesto), funcionarán correctamente, gracias a la existencia de una "suprainstitución" denominada Estado, la idea de garantizar la generación de riqueza en dimensiones importantes, empieza a adoptar otro cariz: "Históricamente el crecimiento de las economías ha ocurrido en el seno del marco institucional de políticas coercitivas bien desarrolladas. No observamos anarquía política en países de altos ingresos" (North, 1993, p. 27).

Significa lo anterior que, si bien un adecuado orden institucional es necesario como marco óptimo para la generación de riqueza, no se puede afirmar que dicho marco se constituya en la manera más eficiente ni más justa, desde el punto de vista individual, en cuanto al acceso a la riqueza. Se puede observar lo paradójico de la afirmación, partiendo del planteamiento institucionalista, en cuanto al surgimiento de las instituciones como el resultado de unas decisiones individuales, pero con la limitación que significa el hecho de que en tales decisiones no participan todos los individuos y más bien las mismas se concentran en aquellos que tienen mayor poder. 
Retomando a Smith, la riqueza es la expresión potencial del poder natural y de la personalidad humana, el egoísmo del individuo puede explicar buena parte del comportamiento económico de los agentes que intervienen en el mercado. Aunque en un marco institucional, esta explicación se debe matizar con el hecho de que normalmente no es posible que absolutamente todos los individuos decidan, es más, lo que ocurre la mayoría de las veces es que son unos cuantos quienes tienen un peso decisorio relevante.

Los derechos de propiedad vehementemente defendidos por Locke y Smith, conforman una de las razones centrales del intercambio en la teoría de los costos de transacción. Su adquisición supone la puesta en marcha de todo un dispositivo que implica un costo; este dispositivo requiere acceso a la información y procedimientos coordinados entre los agentes que participan del intercambio, haciendo complejos los costos de la transacción.

Ante este escenario, las empresas se perfilan como los mediadores más competentes entre los usuarios y el mercado, pues son ellas quienes cuentan con mayor y mejor acceso a la información.

Para abordar el enfoque institucionalista del costo de transacción, resulta interesante la analogía que Williamson presenta en relación con la física:

En los sistemas mecánicos, buscamos las fricciones: ¿encajan los engranajes, están lubricadas las piezas, hay fugas innecesarias u otras pérdidas de energía? La contraparte económica de la fricción es el costo de transacción: ¿operan armoniosamente las partes de la transacción, o hay frecuentes malentendidos y conflictos que generan demoras, descomposturas y otras deficiencias del funcionamiento? (Williamson, 1989, p. 13).

Con este ejemplo de profundo valor explicativo, lo que Williamson nos muestra es que la dinámica de las relaciones económicas se encuentra claramente acelerada o ralentizada, gracias a ese elemento que surge de toda interrelación, que se constituye en un generador de fricción que permite o no una eficiente interacción. Complementa 
Williamson con una referencia a ciertas instituciones y el rol que estas deben jugar:

Contra lo que sostenían algunas concepciones anteriores -donde se explican las instituciones económicas del capitalismo por preferencia a los intereses clasistas, la tecnología o el poder monopólico-, el enfoque del costo de transacción sostiene que estas instituciones tienen el propósito y el efecto fundamental de economizar los costos de transacción (Williamson, 1989, p. 13).

Y para concretar la búsqueda de una definición con respecto a este enfoque, Williamson presenta de manera sucinta lo que para él significa adoptar esta corriente teórica: "La economía del costo de transacción es un enfoque institucional comparado para el estudio de la organización económica donde se convierte la transacción en la unidad básica del análisis" (Williamson, 1989, p. 387).

Es cierto que la teoría de los costos de transacción de la que habla Williamson ${ }^{6}$ proporciona una idea sobre la complejidad instalada en los procesos de intercambio y el interés de los agentes por legitimar el derecho a la propiedad para generar niveles diferenciales de riqueza, aceptando además que el contexto histórico ha privilegiado la formación de riquezas diferenciales acentuando las brechas sociales. La reflexión se sitúa entonces en campos más diversos a los del tradicional conflicto entre producción e ingreso.

Los estudios microeconómicos recientes conceden una gran importancia a la actividad de los agentes económicos para comprender las relaciones de mercado y explicar su rol en los ciclos económicos, a lo cual se puede sumar que, aunque desde el punto de vista microeconómico

6 No se debe olvidar que los planteamientos teóricos propuestos por Oliver Williamson tienen sus raíces en el hecho de haber sido discípulo de Ronald Coase, quien a su vez desarrolló los principios fundamentales del enfoque de costos de transacción. La obra de Coase le mereció el premio Nobel de Economía en el año 1991, precisamente por sus aportes a la ciencia en cuanto a costos de transacción y derechos de propiedad, en el marco de la economía institucional. 
se haga necesaria la agregación de más agentes para comprender mejor el comportamiento del mercado, el estudio de su actividad encuentra sentido en las formas organizacionales que acogen la colectividad propia de estos agentes, cuyo interés es generar acuerdos, contratos o normas que beneficien sus intereses grupales, donde cobra importancia el estudio de estos aspectos y su relación con la pobreza.

De hecho, Williamson otorga un rol de central importancia al ámbito microeconómico, alegando además que dicho ámbito ha sido olvidado por los economistas, cuando es, tal vez, donde se originan los elementos básicos de teoría de los costos de transacción en el marco institucionalista:

La economía del costo de transacción sostiene que las instituciones microeconómicas desempeñan un papel fundamental, sutil y relativamente olvidado en la explicación de la actuación económica diferencial: a través del tiempo, dentro de las industrias y entre ellas, dentro de los Estados nacionales y entre ellos, y en los sistemas sociopolíticos (Williamson, 1989, p. 408).

La sutilidad que menciona Williamson, sea tal vez ese elemento imperceptible que, en el trasfondo de las explicaciones institucionalistas, genera en ocasiones una cierta dificultad para explicar con absoluta claridad el funcionamiento institucional. Muy seguramente, esto obedece precisamente al carácter de abstracción sobre el que se cimienta la teoría microeconómica.

El análisis económico de las organizaciones ha evolucionado particularmente a partir de la década de 1970, como resultado de la evidencia de la acción fundamental que cumplen los agentes como unidades económicas que modifican el curso de las decisiones de mercado.

Los aportes hechos por Coase (1960) y Williamson (1989) permiten comprender mejor por qué la naturaleza de los agentes y la estimación de sus intereses, son fundamentales para tomar decisiones económicas y para dar una lectura más acertada de las nuevas estructuras del mercado.

Sin embargo, y en contraposición a la tendencia hacia un análisis de fuerte base microeconómica, surgen propuestas que propenden por 
un análisis más colectivo de las conformaciones institucionales. Lo que se podría llamar una heterodoxia institucionalista. Swedberg y Granovetter afirman que "[...] las instituciones económicas se construyen gracias a la movilización de recursos por medio de redes sociales, a partir de limitaciones determinadas por el desarrollo histórico anterior de la sociedad, la política, el mercado y la tecnología" (1994, p. 134).

De igual manera, el Estado como "suprainstitución", ampliamente aceptada e incluso reclamada por las diferentes corrientes de lo que se podría llamar una heterodoxia institucionalista, se define como una acumulación de diferentes tipos de capital en un muy largo plazo:

... capital de fuerza física policial o militar (que evoca le definición weberiana del monopolio legítimo de la violencia física); capital cultural e informático acumulado en forma de estadísticas o de instrumentos de conocimiento de validez universal dentro de los límites de su incumbencia, como el sistema de pesas y medidas, la cartografía o el catastro, y un capital simbólico (Bordieu, 2000, p. 25).

Como reflexión final, es claro que una de las preocupaciones centrales de la ciencia económica se encuentra relacionada con la riqueza, abordada esta como concepto y como realidad ${ }^{7}$ desde diferentes enfoques, y reúne no solamente una conceptualización o formalización científica, sino que además referencia aspectos tan disímiles como la

7 De otra parte, una suerte de ausencia de riqueza, se podría interpretar de alguna manera como el antónimo del concepto (pobreza), lo cual se ha convertido en una verdadera preocupación teórica, política y práctica. La pobreza, conmina a un importante porcentaje de la población mundial, sobre todo en economías emergentes, a un presente insostenible y a un futuro aún más incierto. Si bien, a lo largo de este capítulo se ha hecho referencia teórica y práctica a la riqueza, no se puede olvidar que su "contrario" es un aspecto de vital importancia, que ha merecido la atención de múltiples científicos sociales (entre ellos muchos economistas), independientemente del enfoque al que se adhieran. Una evidencia de la importancia y sobre todo la preocupación del mundo en relación con la pobreza, es el haberla constituido como objetivo primordial en la nueva agenda de desarrollo mundial que se acordó durante la Asamblea General de las Naciones Unidas en septiembre de 2015 y que definió los Objetivos de Desarrollo Sostenible (ODS), cuyo horizonte temporal fue establecido para el año 2030. 
percepción humana o social, así como "fricciones", tal como menciona Williamson en cuanto al orden institucional.

Aunque sería imposible agotar la discusión en torno al tema de la riqueza, se han presentado aquí algunos de los aspectos relevantes del debate y el análisis económico y social frente al concepto, en un abordaje desde diferentes ámbitos que ofrece el institucionalismo (y las organizaciones) como corriente de pensamiento económico.

\section{Una aproximación al concepto de vivienda}

El entorno demográfico urbano ha venido sufriendo configuraciones de rápida transformación durante los últimos dos siglos. El impacto que generó la revolución industrial sobre la conformación y el posterior crecimiento de las ciudades, es un fenómeno que hoy día se observa a gran escala.

En estos espacios urbanos, es evidente que una de las principales necesidades obedece a la habitación de quienes allí viven y, este bien, que en muchas economías (principalmente emergentes) se considera inclusive un elemento de la política social ${ }^{8}$, se constituye en una mercancía que contiene múltiples características, desde el punto de vista económico y social.

En primer lugar, debemos mencionar que la vivienda parte de ser una necesidad básica en una ciudad ${ }^{9}$, si habitamos un entorno urbano, las consecuencias de no acceder a una vivienda, pueden resultar catastróficas, además de generar problemáticas de índole social, que van más allá del individuo.

8 Cabe mencionar que el Departamento Administrativo Nacional de Estadísticas (Dane), utiliza el indicador de Necesidades Básicas Insatisfechas (NBI) en sus mediciones, para determinar entre otros aspectos, el déficit y acceso a vivienda de los colombianos y de esa manera, establecer grupos poblaciones en condiciones de pobreza.

9 En el ámbito de lo rural, también es determinante acceder a vivienda, sin embargo, allí el análisis cambia sustancialmente, ya que el entorno y sobre todo la presión de la demanda no es comparable con lo que sucede en entornos urbanos. 
En segundo lugar y, en relación con lo que se ha tratado previamente, la vivienda (inmueble), se constituye en un factor de riqueza, bien sea para aquellos que la poseen como un activo o para aquellos que la poseen simplemente para cubrir la necesidad básica descrita y, por supuesto, también para aquellos que la poseen por motivaciones relacionadas con el "consumo ostensible" explicado por Veblen.

Desde estas acepciones se deben diferenciar, en una clasificación básica, dos tipos de mercados para la vivienda: i) aquel mercado inmobiliario que opera con bajos niveles de intervención o direccionamiento estatal, en el cual interactúan agentes de diversa naturaleza como constructores, sector financiero, compradores y Estado ${ }^{10} \mathrm{y}$, ii) el mercado inmobiliario que busca brindar a un determinado segmento de la población, el acceso a este bien que resulta básico para su bienestar ${ }^{11}$, el cual está determinado por las decisiones gubernamentales y las políticas públicas al respecto.

Para el primer caso, la demanda de vivienda (inmueble), puede estar relacionada con la percepción de riqueza que define Veblen, desde la óptica del consumo ostensible o puede ser una inversión que constituye a la vivienda en un activo que busca generar flujos financieros de retorno, en cuyo caso, también se clasificaría como una forma de riqueza.

En cuanto al acceso a vivienda para cubrir una necesidad básica, existe allí relación con alguna percepción de riqueza por parte de aquellos que acceden a la misma, vista esta como el nivel de satisfacción o utilidad (valor de uso neoclásico) que experimenta. Sin embargo, es

10 El Estado determina y decide en torno a aspectos de central importancia para el mercado de la vivienda, tales como licencias, definición de usos del suelo y subsidios, entre otros. En general, la vivienda ha sido objeto de políticas públicas que, por supuesto, son de exclusiva implementación estatal.

11 En Colombia se han definido dos categorías para este tipo de vivienda: i) Vivienda de Interés Social (VIS), es aquella que reúne los elementos que aseguran su habitabilidad, estándares de calidad en diseño urbanístico, arquitectónico y de construcción cuyo valor máximo es de ciento treinta y cinco salarios mínimos legales mensuales vigentes (135 SMLM) y, ii) Vivienda de Interés Prioritario (VIP), es aquella vivienda de interés social cuyo valor máximo es de setenta salarios mínimos legales mensuales vigentes (70 SMLM). www.minvivienda.gov.co (en línea) consulta efectuada el 1 de marzo de 2017. 
útil sumar a esta afirmación el concepto de felicidad ${ }^{12}$ desde la óptica de un institucionalismo que se fundamenta más en el orden jurídico:

... la búsqueda de la riqueza es más congruente con nuestras instituciones en lo que respecta al comportamiento ético que la búsqueda de la felicidad. [...] el principio de la riqueza puede producir más fácilmente los elementos formales de una teoría ética -incluyendo nociones de derecho y justicia correctiva- que lo que el utilitarismo podría lograr. [...] el principio de riqueza es más concreto que el principio de felicidad" (Posner, 1979, p. 176).

Aquí surge nuevamente la discusión entre institucionalistas con respecto a elementos básicos como las reglas de juego, la historia o los costos de transacción. Es evidente que un individuo busca la felicidad, pero ella puede ser un elemento etéreo que se concreta a través de la obtención de bienes (en este caso vivienda, inmuebles) que representan riqueza, bien sea como inversión o como satisfacción.

En cualquier caso y atendiendo a lo que plantea Posner, el individuo encontraría de manera mucho más concreta y asible la felicidad, siempre que posea riqueza, por lo menos, aquella que le brinda una condición básica de existencia o que le permita proyectar futuros flujos de retorno financiero.

En ese mercado de la vivienda, que está regido por la intervención estatal y por la política pública y que busca brindar el acceso a poblaciones vulnerables o cuyos niveles de ingresos no les permiten acceder por sí mismos a este bien, se evalúa un retorno de índole social y macroeconómico ${ }^{13}$, que de alguna manera podría generar riqueza no

12 Aceptando que la definición neoclásica de satisfacción a nivel individual: i) utilidad total, ii) utilidad media y, iii) utilidad marginal, tiene algo que ver con el concepto de felicidad, por lo menos desde la óptica material, su sumatoria se relacionará a su vez con medidas agregadas como el bienestar o el desarrollo económico.

13 Vale la pena mencionar que la política de crecimiento económico en Colombia, ha estado históricamente ligada al sector de la construcción. Desde el gobierno de Misael Pastrana con el diseño e implementación del UPAC como herramienta de estímulo financiero, este sector ha sido priorizado por muchos gobiernos en su afán de impactar indicadores macroeconómicos en el mediano plazo (PIB, desempleo, etc.). 
solo en los términos individuales ya descritos, sino que también a nivel agregado, por factores como el impulso del sector de la construcción y el mercado de crédito, además de mitigar los riesgos sociales que se pueden generar cuando un alto porcentaje de la población no cubre su necesidad básica de habitación: "La informalidad urbana se produce y se reproduce con altas densidades para acoger familias pobres cuya baja capacidad de pago no les permite satisfacer su necesidad de vivienda a través de mecanismos formales" (Alfonso, 2016, p. 251).

En términos generales, es importante tener en cuenta que el mercado inmobiliario tiene unas características particulares que definen su dinámica y más allá de las motivaciones, regulaciones, intervenciones o ausencias del Estado, así como la interacción de los agentes que lo componen, dichas características no pueden dejarse de lado, ya que resultan esenciales a la hora de abordar un análisis del mercado de vivienda:

En el análisis del mercado inmobiliario y de las políticas públicas relacionadas hay que tener en cuenta que la vivienda, además de ser un activo que representa gran parte de la riqueza de los hogares, es un bien indivisible difícil de transar, con características y ubicación heterogéneas, altos costos de transacción y oferta cuasi inelástica (Salazar et al., 2012, tomado de Cediel y Velásquez, 2015, p. 234).

Además, advierte Ronald Coase (1960), que la esfera de lo social (en la cual se enmarcaría principalmente el mercado de la vivienda auspiciado por programas gubernamentales) y la esfera de lo privado (en la cual se enmarcaría el resto del mercado), muestra elementos que no garantizan la eficiencia plena de su interacción:

El análisis en términos de divergencia entre los productos privado y social centra su atención en las deficiencias particulares del sistema y tiende a alimentar la creencia de que cualquier medida que elimine la deficiencia es necesariamente deseable. Distrae la atención de aquellos otros cambios del sistema que están inevitablemente asociados con la medida correctiva, cambios que pueden producir más daño que la propia deficiencia original (p. 553). 
Se percibe en esta explicación, algo muy similar a la mencionada "fricción" de Williamson.

Analizar distribución de riquezas a partir de los derechos de propiedad que supone el mercado de la vivienda en diferentes ciudades del mundo por ejemplo, brinda un escenario de estudio ideal, para comprender cómo los agentes económicos determinan el comportamiento del sector, abordando las dificultades propias de la teoría de los costos de transacción y de las organizaciones, como la naturaleza del arbitraje de intereses, las asimetrías de información, la incertidumbre y la adecuación o no, a las nuevas estructuras de gobernanza que suponen las organizaciones en la economía del siglo XXI.

Además de los elementos ya mencionados, no se puede olvidar que la demografía es un aspecto adicional que amplía esa gama de fricciones o costos de transacción que influyen en el mercado de vivienda, ya que su evolución necesariamente determinará los niveles de demanda de inmuebles en el mediano y en el largo plazo.

Las economías latinoamericanas en particular, han sufrido modificaciones importantes en su configuración demográfica y, en clara relación con la vivienda, se observa que esto ha determinado la evolución, involución o estancamiento de las ciudades en la región, mostrando en muchos casos dinámicas que se escapan a una planeación gubernamental ordenada, por lo que se potencian fenómenos de asentamiento irregular, que con el paso del tiempo se empiezan a legalizar, más por la presión social y económica que aquellos asentamientos y la sociedad en general ejercen desde sus propias dinámicas, que por objetivos claros de planeación estatal, siendo imposible atender objetivos de planeación urbana previamente establecidos.

En opinión de Alfonso (2016):

La transformación social de América Latina tiene diferentes manifestaciones, una de ellas en el orden residencial, ligado a la intensidad de uso del suelo para vivienda. Como regla, se prefieren las bajas densidades a las más altas. Aunque en las urbes de América Latina, como Bogotá, existen vecindarios de baja densidad en una etapa previa a la regularización de la propiedad y a la legalización ante el Estado (p. 248). 
En ciudades como Bogotá y en muchas otras capitales de Colombia, el fenómeno de asentamientos irregulares se ha visto incrementado por las causas propias del desplazamiento originado por violencia, además del que se genera por razones económicas.

La propiedad del suelo y su connotación de riqueza ha significado una permanente confrontación en las sociedades latinoamericanas en general y en la colombiana en particular. Es claro que estas sociedades no han logrado hacer pleno tránsito, o lo han hecho de manera tardía, entre la sociedad rural agrícola y la sociedad moderna urbana.

Esta característica histórica, no es un hecho menor, ya que se ha constituido en un elemento central en la conformación de las estructuras económicas, sociales y políticas de los países que hacen parte de la región y han determinado también su conformación institucional.

Acemoglu y Robinson (2012), definen dos categorías de instituciones, por un lado están las instituciones económicas inclusivas, que para serlo, deben "[...] ofrecer seguridad de la propiedad privada, un sistema jurídico imparcial y servicios públicos que proporcionen igualdad de condiciones en los que las personas puedan realizar intercambios y firmar contratos [...]" (Acemoglu y Robinson, 2012, p. 96) y, por otra parte, están las instituciones económicas extractivas que se definen asî "porque tienen como objetivo extraer rentas y riqueza de un subconjunto de la sociedad para beneficiar a un subconjunto distinto" (Acemoglu y Robinson, 2012, p. 98).

Tomando como referencia a esta última categoría, se deduce con facilidad que esta ha sido la característica de las instituciones latinoamericanas, sobre todo en lo que tiene que ver con el uso de la tierra ${ }^{14}$,

14 Han sido los terratenientes quienes, en diferentes épocas de la historia latinoamericana y colombiana, han definido el derrotero de la economía, motivados por el afán rentístico que se observa en sus decisiones. Bien lo explica Kalmanovitz, en relación con el tránsito de la economía agrícola a la industrial en Colombia durante el siglo XIx: “[...] para consolidar en su conjunto un regresivo sistema de haciendas que logra en gran medida monopolizar la tierra y someter un importante sector de la población a la servidumbre" (Kalmanovitz, 1994, p. 93). El Estado latinoamericano se ha caracterizado por una inexistente frontera entre lo público y lo privado, en la cual los intereses privados han hecho connivencia con las decisiones públicas en el escenario político. En otras palabras, el Estado decide influenciado por y para algunos privados, o en el peor 
la trayectoria histórica muestra una fuerte tendencia a consolidar instituciones de este tipo, las cuales, se ven reproducidas en las ciudades.

Cuando se piensa en la propiedad del suelo, la concentración de la riqueza en este aspecto ${ }^{15}$ ha configurado un mercado que, además, tiene matices especulativos, con lo cual se afecta seriamente la posibilidad de acceso, sobre todo para aquellos que se encuentran a expensas de lo que defina la política pública de vivienda.

Desde una perspectiva estructuralista, lo que se vive en lo rural, por parte de los campesinos despojados de tierra, es prácticamente lo mismo que se vive en lo urbano con los trabajadores despojados de vivienda y ello a su vez, es causa de un bajo nivel decisorio también en lo político, escenario en el cual tiene lugar la consolidación del orden institucional. Al respecto Furtado (1965) señala:

El objetivo político a lograr en los países subdesarrollados -es decir, el objetivo cuya consecución asegurará un desarrollo económico más rápido en una sociedad democrática pluralista-, consiste en crear las condiciones para que los asalariados urbanos y la masa campesina tengan una participación directa en el proceso de formación del poder (p. 85).

Si existe un alto porcentaje de la población en condiciones de pobreza que no accede a bienes básicos como la vivienda, difícilmente estarán en condiciones de reflexionar sobre su participación política y mucho menos estarán en disposición de participar y discutir sobre la formación del poder y de un orden institucional que les permita mejorar su situación, lo cual, evidentemente, se constituye en un círculo

de los casos el Estado es conformado por los privados en una doble naturaleza, que resulta perversa para la consolidación de un escenario de lo público, en el cual, las necesidades ciudadanas y generales sean las que guíen las decisiones gubernamentales.

15 El cuadro III.16. Índice de Gini de propiedad de la tierra (1880-1990), que presentan Bértola y Ocampo (2013, p. 151), muestra que para América Latina el índice se ubica en 0,799 , mientras que en Asia se ubica en 0,443, en países bálticos y escandinavos en 0,484 y en Estados Unidos y Canadá en 0,532. 
vicioso que debe ser superado mediante una ruptura, también de orden institucional, acudiendo a todas las formas y vertientes que este adopta.

\section{Conclusiones}

Riqueza y vivienda, son conceptos que se muestran claramente relacionados a lo largo de la historia; el primero de ellos (la riqueza) es una realidad, que hace parte de la vida misma del ser humano siendo inherente a su evolución, bajo las diferentes acepciones históricas, filosóficas, sociales y económicas que se le quieran otorgar y sus manifestaciones han generado profundas transformaciones en la humanidad. El segundo concepto (vivienda), puede abordarse desde la necesidad que ello significa para el ser humano, así como desde la óptica del activo que representa y, ampliando la conceptualización, desde su relación con la riqueza.

El abordaje interdisciplinar del concepto de riqueza permite evidenciar que, según el contexto histórico, las relaciones de mercado han favorecido el surgimiento de agentes económicos de diversa índole que determinan el comportamiento del mismo. En dicho contexto, el comportamiento de los agentes responde a la lógica propia del capitalismo que propugna por un status quo, del mantenimiento de un sistema diferencial de generación de rentas, que le permite influir en el comportamiento de terceros para generar mejores condiciones de mercado.

El enfoque institucionalista en general y la economía de las organizaciones en particular, se constituyen en una plataforma desde la cual se pueden analizar los dos conceptos en perspectiva general, histórica e interdisciplinaria que permite incluir aspectos que trascienden lo económico, además de brindar la posibilidad de incluir propuestas como la teoría de los costos de transacción, que también acude a otras ciencias o disciplinas para complementarse.

Los agentes económicos estarían llamados a reducir los costos de transacción, buscando el mejor resultado en el juego entre los mercados y las distintas actividades económicas. Desde esta perspectiva, partir del análisis de las organizaciones, brinda elementos para comprender la naturaleza compleja de las relaciones entre los individuos 
y los desafíos que suponen para la economía, el establecimiento de acuerdos que respondan a las expectativas de los agentes teniendo presentes los intereses divergentes, la ponderación desigual frente al riesgo, la diferencia de esfuerzos, la asimetría en la información y la necesidad de influir sobre el comportamiento de los demás agentes en beneficio de sus intereses.

Lo complejo de la estructura de las organizaciones que integran los agentes, reposa en parte en los altos costos que genera el derecho de propiedad. Si bien, realizar estudios comparados es útil para abordar las dimensiones que son objeto de la investigación en curso, las relaciones que se tejen en el seno de las organizaciones, sugieren una prudente distancia que permita caracterizar la naturaleza de los agentes y el rol sistémico que desempeñan en la generación de riqueza.

De la aproximación teórica presentada, tal vez uno de los elementos de mayor relevancia sea esa característica multivariada del enfoque institucionalista que incluye propuestas y análisis interdisciplinares, lo cual permite abordar los conceptos tratados desde una perspectiva comparada, que además utiliza elementos de carácter histórico y su incidencia actual.

Queda claro que uno y otro concepto (riqueza y vivienda) son de amplio alcance y que, sobre todo, el término riqueza ha sido ampliamente tratado, por lo cual los acercamientos teóricos y conceptuales presentados aquí quedan abiertos a ser complementados, además de sugerir interrogantes -aunque no explícitamente-, que abren interesantes ventanas de investigación.

\section{Referencias}

Acemoglu, D., y Robinson, J. (2012). Por qué fracasan los países. Barcelona, España: Editorial Deusto.

Alfonso, O. (2016). La calidad de la densidad urbana en Bogotá. Revista de Economía Institucional, Vol. 18, № 34.

Bértola, L., y Ocampo, J. A. (2013). El desarrollo económico de América Latina después de la Independencia. México D. F., México: Fondo de Cultura Económica. 
Bourdieu, P. (1997). Le champ économique. Actes de la recherche en sciences sociales, 119(1), 48-66.

Cediel, V., y Velásquez, C. (2015) ¿Hay una burbuja inmobiliaria en Bogotá? Un estudio por segmentos de mercado. Revista de Economía Institucional, Vol. 17, $\mathrm{N}^{\circ} 32$.

Coase, R. (1960). El problema del costo social. En Derecho y economía: una revisión de la literatura. México D. F., México: Fondo de Cultura Económica. 2000.

Chang, H-J. (2006), La relación entre las instituciones y el desarrollo económico. Problemas teóricos claves. Revista de Economía Institucional, Vol. 8, $\mathrm{N}^{\circ} 14$.

Furtado, C. (1965). Dialéctica del Desarrollo. Bogotá D. E., Colombia: Fondo de Cultura Económica.

Kalmanovitz, S. (1994). Economía y nación. Una breve historia de Colombia. Bogotá D. C., Colombia: Tercer Mundo Editores.

Kalmanovitz, S. (2011). Las consecuencias económicas de la Independencia en América Latina. En Institucionalidad y Desarrollo Económico en América Latina. Comisión Económica para América Latina y el Caribe (CEPAL). Kitch, E. (1983). Los fundamentos intelectuales del análisis económico del derecho. En Derecho y economía: una revisión de la literatura. México D. F., México: Fondo de Cultura Económica. 2000.

Locke, J. (1821). Two Treatises on Goverment. (http://www.bartleby.com/169/, Ed.) London, UK: R. Butler.

North, D. (1993). Instituciones, cambio institucional y desempeño económico. México D. F., México: Fondo de Cultura Económica.

Polanyi, K. (1944). La gran transformación: crítica del liberalismo económico. Madrid, España: Las Ediciones de La Piqueta. 1989.

Posner, R. (1979). Utilitarismo: Economía y Teoría Jurídica. En Derecho y economía: una revisión de la literatura. México D. F., México: Fondo de Cultura Económica. 2000.

Salazar, N., Steiner, R., Becerra, A, y Ramírez, J. (2012). ¿Qué tan desalineados están los precios de la vivienda en Colombia? Bogotá D. C., Colombia: Fedesarrollo. 
Seckler, D. (1977). Thorstein Veblen y el Institucionalismo: Un estudio de la filosofía social de la economía. México D. F., México: Fondo de Cultura Económica.

Smith, A. (1776). An Inquiry into the Nature and Causes of the Wealth of Nations. London, UK: W. Strahan \& T. Cadell. En español: Una investigación sobre la naturaleza y causa de la riqueza de las naciones.

Swedberg, R., \& Granovetter, M. (1994). La sociologie économique. Les propositions fondamentales de la sociologie économique. Pour une autre économie, 115-140.

Veblen, T. (1899). Teoría de la clase ociosa. Buenos Aires, Argentina: Ediciones El Aleph. 2000.

Williamson, O. (1989). Las instituciones económicas del capitalismo. México D. F., México: Fondo de Cultura Económica. 